\title{
Vasopressin in Oligohydramnios-Induced Lung Hypoplasia
}

\author{
CALVIN T. SHEN, ADRIEN C. MOESSINGER, GEORGE T. KIU, AND L. STANLEY JAMES \\ Department of Pediatrics, Division of Perinatal Medicine, College of Physicians and Surgeons of Columbia \\ University, New York, New York 10032
}

\begin{abstract}
Experimentally-induced oligohydramnios (oligo) produces lung hypoplasia. To determine if arginine vasopressin (AVP), a hormone known to decrease fetal lung fluid production, contributes to the pathogenesis of oligo-induced lung hypoplasia, the following experiment was performed. Brattleboro rats were mated to produce litters either with AVP [heterozygotes (HZ)] or without AVP [homozygotes (HO)]. On d 15 of gestation, half of each litter underwent amniocentesis to create persistent oligo. Littermates with intact membranes served as controls. Four groups of fetuses, i.e. $10 \mathrm{HO}$ litters divided into control (44 fetuses) and oligo (25 fetuses), and eight $\mathrm{HZ}$ litters divided into control (35 fetuses) and oligo (18 fetuses), were killed at term for measurement of organ weights and biochemical determination of lung development. Significant differences between control and oligo groups were observed for body weight $(\mathrm{HO}, p=0.008$; $\mathrm{HZ}, p=0.03)$, lung weight $(<0.001$ for both crossings), lung/body weight ratio ( $<0.001$ for both), DNA per lung $(\mathrm{HO}, p=0.02 ; \mathrm{HZ}, p<0.001$ ), and lung dry/wet ratio (HO, $p<0.001 ; \mathrm{HZ}, p=0.001)$. Oligo groups with and without AVP were not found to be different for lung weight ( $p=0.217)$, lung/body weight ratio $(p=0.209)$, and DNA per lung $(p=0.822)$. An analysis of variance confirmed the lack of any significant difference of the impact of oligo in the presence or absence of AVP. We conclude that AVP plays no role in the development of oligo-induced lung hypoplasia. (Pediatr Res 28: 595-598, 1990)
\end{abstract}

\section{Abbreviations}

AVP, arginine vasopressin

oligo, oligohydramnios

HZ, heterozygotes

HO, homozygotes

Congenital lung hypoplasia is a major cause of early neonatal mortality. A recent autopsy series of 419 consecutive early neonatal deaths over a 15-y period (1) reported that prevalence of lung hypoplasia increased from 13 to $22 \%$ while other pulmonary pathologies decreased, perhaps reflecting improved prevention and care of these other pathologies (e.g. hyaline membrane disease, meconium aspiration, pneumonia). In $27 \%$ of the cases in the above series, lung hypoplasia was associated with oligo, although the pathogenesis remains elusive.

Lung growth is disturbed if fetal lung fluid volume is not maintained within normal limits. Lung volume in the fetus appears to be maintained by intrinsic forces acting from within

Received March 8, 1990; accepted July 10, 1990.

Correspondence: Calvin T. Shen, M.D., Morristown Memorial Hospital, 100 Madison Ave., Morristown, NJ 07962. the organ itself (e.g. secretion/retention of fetal lung fluid) $(2,3)$ and by extrinsic forces, both phasic and tonic $(4,5)$, that expand the lung from the outside (fetal breathing and chest wall recoil). Because fetal breathing activity is not markedly altered by oligo $(6-8)$, it is conceivable that oligo leads to lung hypoplasia by an alteration in fetal lung fluid secretion/retention, thereby reducing fluid volume within the lungs.

Lung fluid production is decreased by intravascular infusion of AVP $(9,10)$. $\beta$-Adrenergic agents have also been shown to decrease lung fluid production, but this effect may be mediated by AVP (11). These observations, coupled with the fact that AVP is released in response to various forms of fetal stress (12-14), led to the hypothesis that chronic oligo may cause a rise in AVP, thus altering fetal lung fluid balance and adversely affecting lung growth.

We have shown previously that experimentally induced oligo in the Sprague-Dawley rat leads to lung hypoplasia (15). In this study, we have used the Brattleboro rat, a Long Evans mutant strain lacking detectable AVP production (16), to evaluate whether oligo in the absence of endogenous AVP also leads to lung hypoplasia.

\section{MATERIALS AND METHODS}

Pregnant Brattleboro rats were obtained from Blue Spruce Farms (Indianapolis, IN), with presence of sperm in the vaginal smear taken to indicate d 0 of gestation. Rats were housed individually and provided food and water ad libitum. Two types of crossings were used (Fig. 1). A female homozygous for the trait of diabetes insipidus was mated with either a homozygous affected male or a Long Evans male with urinary concentrating ability. These matings gave rise to two types of litters: 1 ) $\mathrm{HO}$ without AVP and 2) HZ with AVP. Thus, each dam carried fetuses of one genotype. Although evidence exists that AVP does

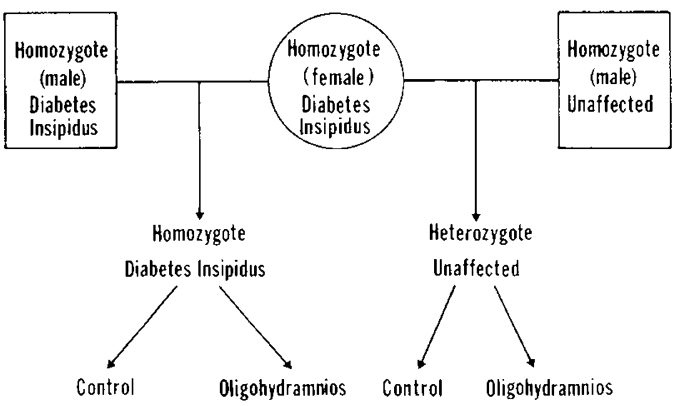

Fig. 1. The two types of experimental crossings performed. Females homozygous for the recessive trait of diabetes insipidus were mated with either homozygous affected males or homozygous unaffected males to give rise to two types of litters: $\mathrm{HO}$ with diabetes insipidus or $\mathrm{HZ}$ without diabetes insipidus. In each litter, one half served as the experimental group and underwent amniocentesis to create persistent oligo and the other half served as controls. Thus, four populations of fetuses were created. 
not cross the placenta (17), using an affected female further ensures no maternal AVP effect on the fetuses.

On d 15 of gestation, a median laparotomy was performed under ether anesthesia with local lidocaine infiltration. Both uterine horns were exposed and the number and location of fetuses recorded. One horn was chosen at random and, after careful visualization of each fetus, transuterine punctures of the fetal membranes were performed using a 22-gauge needle. Due to the persistence of the inverted yolk sac containing exocoele fluid (18), three separate punctures were made to ensure entry into the amniotic sac and included one puncture extending into the animal's buttocks. We chose d 15 to maximize impact on lung development and because AVP-synthesizing neurons of the hypothalamus are found on 13 to 17 of gestation in Sprague Dawley rats (19).

Untouched littermates from the other horn served as controls. If the number of fetuses in each horn differed by more than three, fetuses were then numbered by uterine position and either all odd- or all even-numbered fetuses were selected for amniocentesis. After recovery from surgery, the animals were returned to their individual cages until term.

At term, d 21 of gestation, an abdominal hysterectomy was performed under ether anesthesia, then the mother was killed. The excised uterus was placed on ice until all fetal movements ceased. After determination of the experimental status by uterine position, the fetuses and placentas were removed and weighed. Litters were then dissected on ice for placenta, lung, liver, heart, and brain and immediately weighed on a Mettler scale to the nearest $0.1 \mathrm{mg}$.

Lung tissue was frozen at $-70^{\circ} \mathrm{C}$ and then lyophilized for biochemical studies. Due to the small amounts of lung tissue per fetus, lungs were pooled by litter before biochemical studies. Lung DNA and protein were measured by UV absorption according to the methods of Munro and Fleck (20) and Lowry et al. (21). Initially, DNA UV absorptions were measured before RNA extractions, and due to limitations in the amount of

Table 1. Summary of overall morbidity and mortality

\begin{tabular}{|c|c|c|c|c|}
\hline & \multicolumn{2}{|c|}{$\begin{array}{c}\text { HO litters } \\
(n=10)\end{array}$} & \multicolumn{2}{|c|}{$\begin{array}{l}\text { HZ litters } \\
(n=8)\end{array}$} \\
\hline & Control & Oligo & Control & Oligo \\
\hline \multicolumn{5}{|l|}{ At d 15} \\
\hline Fetuses $(n)$ & 44 & 57 & 35 & 41 \\
\hline \multicolumn{5}{|l|}{ At $d 21$} \\
\hline Live fetuses $(n)$ & 44 & 25 & 35 & 18 \\
\hline Survival rate $(\%)$ & 100 & 43.9 & 100 & 43.9 \\
\hline Deformed fetuses $(n)$ & 0 & 13 & 0 & 11 \\
\hline Deformation rate $(\%)$ & 0 & 52 & 0 & 61 \\
\hline
\end{tabular}

specimen available for analysis, not all specimens could be reassayed. Ten pools of lung (eight control and two experimental) were available to be extracted for RNA. The amount of DNA was found to be $62.51 \pm 4.32 \%$ of the nucleic acid. Thus, initial values were adjusted accordingly.

Mean values per litter were used for data analysis, each litter thus carrying equal statistical weight. Statistical analysis within each crossing was done using paired $t$ test by litter to evaluate the impact of oligo on lung growth. Group $t$ tests between crossings and a one-way analysis of variance were used to determine if the effect of oligo on lung hypoplasia differed in the presence or absence of AVP.

This study was approved by the institutional animal care committee.

\section{RESULTS}

The study population is summarized in Table 1. Altogether $10 \mathrm{HO}$ and eight $\mathrm{HZ}$ litters were available for statistical analyses. This includes $69 \mathrm{HO}$ fetuses (44 control and 25 experimental) and $53 \mathrm{HZ}$ fetuses ( 35 control and 18 experimental). Fetal resorption after amniocentesis was $56.1 \%$ in both $\mathrm{HO}$ and $\mathrm{HZ}$ litters. Fetal deformities related to oligo have been described previously in Long Evans rats and include limb/tail/neck contractures, micrognathia, and cleft palate (22). In the oligo groups, one or more of these deformities were noted in 13 of $25 \mathrm{HO}$ and 11 of $18 \mathrm{HZ}$.

Data were collected and analyzed by litter to derive mean outcome variables for control and experimental animals. Litter means were then used to generate means and SD for all four populations of fetuses. These data are summarized in Table 2. Experimental animals weighed significantly less than littermate controls ( $p=0.008$ in $\mathrm{HO} ; p=0.03$ in $\mathrm{HZ}$ litters). Lung, brain, and heart in $\mathrm{HO}$ litters and lung weights in HZ litters were significantly different between controls and experimentals $(\mathrm{p}<$ 0.05 ). However, when expressed as organ/body weight ratios to standardize for discrepancies in overall fetal body sizes, only the lung/body weight ratio remained significant in both types of litters at $p<0.001$, confirming the selective pattern of lung hypoplasia. Also of note, the experimental lungs in both crossings contained significantly less water $(p<0.001)$.

Biochemical analyses of lung tissues are presented in Table 3. One HO litter sample was lost before DNA/protein extractions. In the oligo groups, not only did lungs weigh much less than those of controls (wet lung experimentals $=83.4 \%$ of controls in $\mathrm{HO}$ and $78.6 \%$ in $\mathrm{HZ}$ with both $p$ values $<0.001$ ), but they also contained less DNA (experimentals $=87.2 \%$ of controls in $\mathrm{HO}$ and $83.7 \%$ in $\mathrm{HZ}$ with respective $p$ values of 0.02 and 0.001 ).

Table 4 presents data comparing AVP-deficient (HO) and AVP-present (HZ) groups that were subjected to oligo. A com-

Table 2. Body and organ wt and organ/body ratios

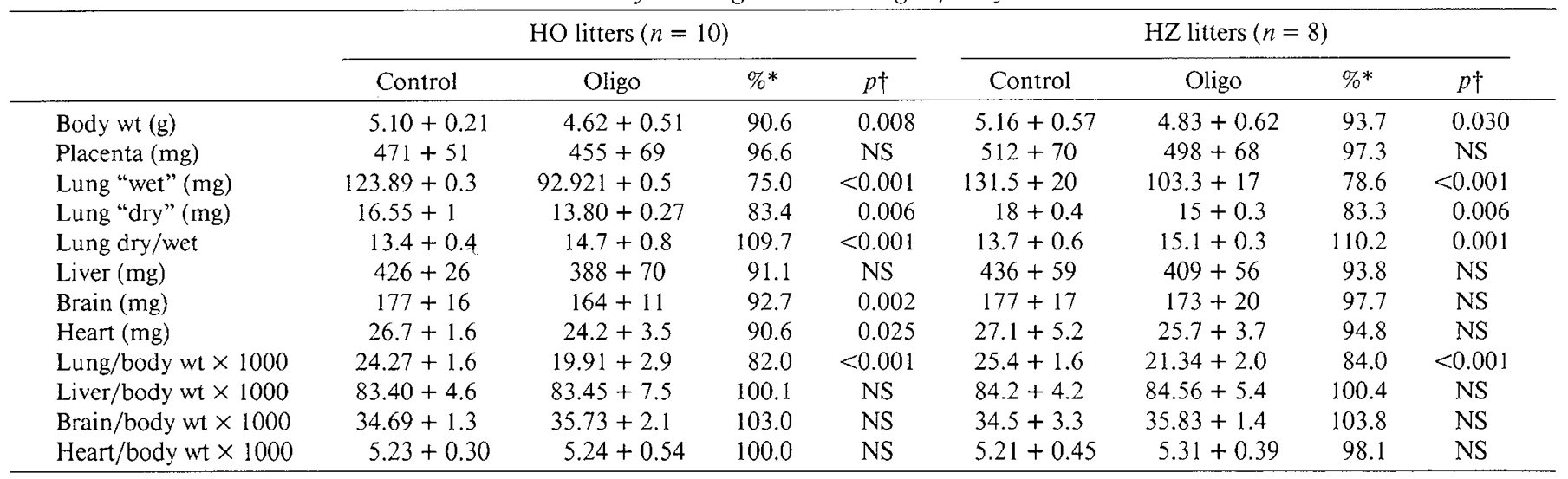

* Value of oligo fetus expressed as a percent of control fetus.

$\dagger$ NS implies $p>0.05$. 
Table 3. Biochemical analysis of lung tissue

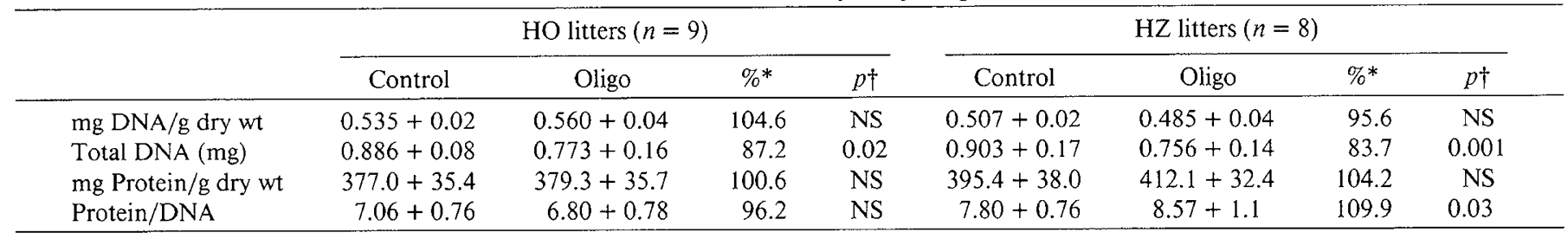

$*$ Value of oligo fetus expressed as a percent of control fetus.

$\dagger$ NS implies $p>0.05$.

Table 4. Comparison of oligo groups with or without AVP

\begin{tabular}{lcc}
\hline & \multicolumn{2}{c}{$\begin{array}{c}\text { HO vs HZ groups } \\
\text { by group } t \text { test }\end{array}$} \\
\cline { 2 - 3 } & $\mathrm{HO} / \mathrm{HZ}(\%)^{*}$ & $p \dagger$ \\
\hline Body wt & 95.6 & $\mathrm{NS}$ \\
Lung "wet" & 89.9 & $\mathrm{NS}$ \\
Lung "dry" & 93.3 & $\mathrm{NS}$ \\
Lung dry/wet & 97.4 & $\mathrm{NS}$ \\
"Wet" lung/body & 93.3 & $\mathrm{NS}$ \\
Liver & 94.8 & $\mathrm{NS}$ \\
Brain & 94.8 & $\mathrm{NS}$ \\
Heart & 94.2 & $\mathrm{NS}$ \\
& & \\
DNA/g dry lung & 115.5 & 0.002 \\
DNA/lung & 102.2 & $\mathrm{NS}$ \\
Lung protein & 92.1 & $\mathrm{NS}$ \\
Protein/DNA ratio (lung) & 79.3 & 0.003 \\
\hline
\end{tabular}

* Values for HO fetuses are expressed in percent of $\mathrm{HZ}$ fetuses. $\dagger$ NS implies $p>0.05$.

parison of the variables most significantly affected by oligo, lung (wet and dry) weights, lung/body ratios, and total lung DNA, found that they were not statistically different. Significant differences were found in the amount of DNA/g tissue and in the protein/DNA ratio, an index of cell size.

A one-way analysis of variance was used to compare the relative magnitude of lung hypoplasia between the $\mathrm{HO}$ and $\mathrm{HZ}$ litters by examining lung/body weight ratio and total lung DNA content. For lung/body weight ratio, the $F$ value was 1.608 with $p=0.213$; for total lung DNA, $F=0.019$ and $p=0.891$.

\section{DISCUSSION}

The Brattleboro rat offers a unique opportunity to assess the role of AVP in the physiopathology of various disease processes. AVP has been shown to decrease fetal lung fluid production ( 9 , $10,23)$. We hypothesized that amniotic fluid drainage resulting in oligo, which is known to impair fetal lung growth and development $(15,24,25)$, could do so by triggering a surge in AVP levels, thus decreasing fetal lung fluid volume.

We were unable to demonstrate a significant difference in the effect of oligo on fetal lung growth between normal fetuses with AVP and fetuses selectively deficient in AVP. Therefore, we conclude that it is unlikely that AVP plays a role in the pathogenesis of oligo-induced lung hypoplasia.

Our resorption rate of $56.1 \%$ is somewhat less than that in a previous study (22) with $80 \%$ resorption after amniocentesis on d 15 of gestation. This disparity is not likely related to fetal absence of AVP, inasmuch as $\mathrm{HO}$ and $\mathrm{HZ}$ litters shared identical resorption rates. Similarly, no difference in the rate of deformations associated with oligo in rats was found to be related to presence or absence of AVP.

These results confirm that oligo secondary to amniocentesis in the rat leads to a selective pattern of fetal growth retardation with the predominant impact on lung growth $(15,25)$. These data further demonstrate that lack of amniotic fluid affects the hydration of the fetal lungs by decreasing dry/wet weight ratio, a point suggested by two previous studies $(6,25)$, where, for technical reasons, fetal lung volumes were not measured directly. However, in a sheep preparation (7), lung fluid volume was measured and found to decrease within $48 \mathrm{~h}$ of amniotic fluid drainage.

Although AVP has been thought to mediate lung fluid resorption at birth, in our study, it did not appear to affect hydration of the fetal lungs. No difference was found in the lung dry/wet ratios comparing $\mathrm{HZ}$ controls to $\mathrm{HO}$ controls (i.e. in the presence and absence of AVP) and $\mathrm{HZ}$ experimentals to $\mathrm{HO}$ experimentals. This finding may be related to the mode of delivery (cesarean section before labor in this study), inasmuch as AVP levels are significantly higher in vaginal deliveries after labor $(14,26)$. The unexpected statistical difference in the amount of DNA/g tissue and lung protein/DNA ratio between experimental groups may be a strain-specific finding, but otherwise is of unclear meaning.

Further support for our main conclusion can be found in experiments of nature, i.e. human anencephalies who often have disturbed hypothalamic function. Anencephaly is associated with polyhydramnios and, more interestingly, lung hypoplasia (27) in a hormonal milieu that may lack AVP (28). Interestingly, Oosterbaan et al. (17) did not find increased amniotic fluid in AVPdeficient Brattleboro rats at term. However, one might argue that subtle differences in amniotic fluid amount might have been more easily detected earlier in gestation, inasmuch as amniotic fluid decreases toward term (29).

Three points should be mentioned that may mitigate the conclusions drawn from this animal model. First, HZ Brattleboro rats have slightly abnormal urinary concentrating ability, and, at least in aged rats, cannot generate AVP levels as high as those produced by Long Evans rats in response to water deprivation (16). Second, it has been shown that in sheep, amniotic AVP is swallowed and resorbed in an active form (30), but leakage of amniotic fluid in our model may interfere with this recirculation. The combination of these factors potentially does not allow the experimental fetuses to achieve the peak AVP levels one might otherwise reach with normal rats in utero. Third, although the Brattleboro rat was previously considered a single gene deletion, new evidence points to a translational defect, possibly specific to brain tissue (31). Given that AVP can be produced in gonads, adrenals, and lungs, one cannot exclude a possible paracrine effect of this peptide on lung tissue.

Acute oligo in sheep has been found to induce a $20-30 \%$ decrease in the volume of fetal lung fluid $(6,7,32)$. This change in fluid volume was not associated with a rise in the level of hormones implicated in fetal lung fluid balance, i.e. catecholamines, cortisol (7), or AVP, as can be extrapolated from this study. It is conceivable that the decrease in fetal lung fluid volume results from simple mechanical compression by the uterus on the fetal thorax or abdomen with resultant elevation of the diaphragm (8). Another possibility is that oligo may affect fetal circulation and decrease pulmonary blood flow through either mechanical or humoral means. Yet another possibility is that the fetus in a state of decreased amniotic fluid becomes in turn hypovolemic, which might directly impact on pulmonary blood flow or indirectly affect fetal fluid balance and impact on hydration of the lung compartment. 
In summary, using a validated model of lung hypoplasia secondary to oligo, we found that AVP, a hormone important in lung/fetal fluid balance, does not affect the development of lung hypoplasia.

Acknowledgment. The authors thank K. F. Schulze and R. I. Stark for their detailed manuscript review.

\section{REFERENCES}

1. Moessinger AC, Santiago A, Paneth NS, Rey HR, Blanc WA, Driscoll JD 1989 Time trends in necropsy prevalence and birth prevalence of lung hypoplasia. Paediatric \& Perinatal Epidemiology 3:440-450

2. Alcorn D, Adamson TM, Lambert TF, Maloney JE, Ritchie BC, Robinson PM 1977 Morphological effects of chronic tracheal ligation and drainage in the fetal lamb lung. J Anat 123:649-660

3. Fewell JE, Hislop A, Kitterman JA, Johnson P 1983 Effect of tracheostomy on lung development in fetal lambs. J Appl Physiol 55:1103-1108

4. Wigglesworth JS, Desai R 1979 Effects on lung growth of cervical cord transection in the rabbit fetus. Early Hum Dev 3:51-65

5. Liggins GC, Vilos GA, Campos GA, Kitterman JA, Lee CH 1981 The effect of bilateral thoracoplasty in fetal sheep. J Dev Physiol 3:275-282

6. Moessinger AC, Fewell JE, Stark RI, Collins MK, Daniel SS, Singh M, Blanc WA, Kleinerman J, James LS 1985 Lung hypoplasia and breathing movements following oligohydramnios in fetal lambs. In: Jones CT, Nathanielsz P (eds) The Physiological Development of the Fetus and Newborn. Academic Press, London, pp 293-298

7. Savich RD, Guerra FA, Lee CH, Kitterman JA 1988 Effects of acute oligohydramnios on the respiratory system of fetal sheep. Pediatr Res 23:524A (abstr)

8. Harding R, Dickson KA, Hooper SB 1989 Fetal breathing, tracheal fluid movement and lung growth. In: Gluckman PD, Johnston BM, Nathanielsz PW (eds) Advances in Fetal Physiology. Perinatology Press, Ithaca, NY, pp 153-175

9. Perks AM, Cassin S 1982 The effects of arginine vasopressin and other factors in the production of lung liquid in fetal goats. Chest 81 (suppl):63s-65s

10. Ross MG, Ervin G, Leake RD, Fu P, Fisher DA 1984 Fetal lung liquid regulation by neuropeptides. Am J Obstet Gynecol 150:421-425

11. Berl T, Cadnapaphornchai P, Harbottle JA, Schrier RW 1974 Mechanism of stimulation of vasopressin release during beta-adrenergic stimulation with isoproterenol. J Clin Invest 53:857-867

12. Daniel SS, Stark RI, Zubrow AB, Fox HE, Husain MK, James LS 1983 Factors in the release of vasopressin by the hypoxic fetus. Endocrinology 113:16231628

13. Oosterbaan HP, Swaab DF, Boer GJ 1985 Increased amniotic vasopressin levels in experimentally growth retarded rat fetuses. J Dev Physiol 7:89-97
14. Oosterbaan HP, Swaab DF 1985 Amniotic oxytocin and vasopressin levels in relation to human fetal development and labor. Thesis, University of Amsterdam. Rodopi Publisher, Amsterdam, pp 87-110

15. Moessinger AC, Bassi G, Collins MH, James LS, Blanc WA 1983 Experimental production of pulmonary hypoplasia following amniocentesis and oligohydramnios. Early Hum Dev 8:343-350

16. Sladek CD, McNeill TH 1982 The Brattleboro heterozygote as a model for neurohypophyseal aging: vasopressin response to dehydration. In: Sokol HW, Valentin H (eds) The Brattleboro Rat. Annals of New York Academy of Science, New York, pp 173-176

17. Oosterbaan HP, Swaab DF, Boer GJ 1985 Oxytocin and vasopressin in the rat do not readily pass from the mother to the amniotic fluid late in pregnancy. J Dev Physiol 7:55-62

18. Adolph EF 1967 Ontogeny of volume regulation in embryonic extracellular fluids. Q Rev Biol 42:1-39

19. Sinding C, Robinson AG, Seif SM, Schmid PG 1980 Neurohyphyseal peptides in the developing rat fetus. Brain Res 195:177-186

20. Munro HN, Fleck A 1966 Recent developments in the measurement of nucleic acids in biological material. Analyst 91:78-88

21. Lowry DH, Rosebrough NJ, Farr AL, Randall RJ 1951 Protein measurement with the folin phenol reagent. J Biol Chem 193:265-275

22. DeMyer W, Baird I 1969 Mortality and skeletal malformations from amniocentesis and oligohydramnios in rats: cleft palate, club foot, microstomia and adactyly. Teratology 2:33-38

23. Wallace MJ, Hooper SB, Harding R 1990 Regulation of lung liquid secretion by arginine vasopressin in fetal sheep. Am J Physiol 258:R 104-R111

24. Symchych PS, Winchester P 1978 Animal models of human disease: Potter's syndrome. Am J Pathol 90:779-782

25. Blachford KG, Thurlbeck WM 1987 Lung growth and maturation in experimental oligohydramnios in the rat. Pediatr Pulmonol 3:328-333

26. DeVane GW, Porter JC 1980 An apparent stress induced release of arginine vasopressin by human neonates. J Clin Endocrinol Metab 51:1412-1416

27. Cooney TP, Thurlbeck WM 1985 Lung growth and development in anencephaly and hydranencephaly. Am Rev Respir Dis 132:596-601

28. Honnebier WJ, Swaab DF 1973 The influence of anencephaly upon intrauterine growth of fetus and placenta and upon gestation length. J Obstet Gynaecol Br Common 80:577-588

29. Tam PPL, Chan STH 1977 Changes in the composition of maternal plasma, fetal plasma and fetal extraembryonic fluid during gestation in the rat. $\mathbf{J}$ Reprod Fertil 51:41-51

30. Ervin MG, Ross MG, Leake RD, Fisher DA 1986 Fetal recirculation of amniotic fluid arginine vasopressin. Am J Physiol 250:E253-E258

31. Majzoub JA, Carrazana EJ, Shulman JS, Baker KJ, Emanuel RL 1987 Defective regulation of vasopressin gene expression in Brattleboro rats. Am $\mathbf{J}$ Physiol 252:E637-E642.

32. Dickson KA, Harding R 1989 Decline in lung liquid volume and secretion rate during oligohydramnios. J Appl Physiol 67(6):2401-2407 